\title{
Chapters, Volumes, Editors! Oh My! Reassessing the Role of Edited Volumes in the Social Sciences
}

David L. Leal, University of Texas at Austin

ABSTRACT Many scholars discount the value of edited volumes and book chapters to the social science enterprise. Nevertheless, these unique formats advance scholarship, help faculty and graduate students achieve their goals, and enhance teaching and learning. This article therefore assesses the criticisms of volumes and chapters, reconsiders the contributions of these publications, and makes recommendations for improving their accessibility and status.

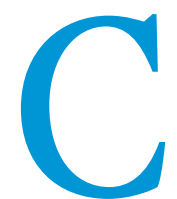

hapters written for edited volumes are the Rodney Dangerfields of intellectual products. We tend to see them as lighter fare, appetizers to the main dishes of journal articles and books. The latter are viewed as more substantive and better-vetted products, and chapters are relegated to a position just above the newspaper op-ed piece. The conventional wisdom says that real scholarly work is found elsewhere. When we read a CV, it is easy to skip over them. Even if some CVs categorize them as "Peer Reviewed Book Chapters," we think we know better. Little wonder chapters often count for little in tenure, promotion, hiring, and "merit raise" decisions.

If you think writing chapters is thankless, imagine editing a volume. I should know-my seventh co-edited volume is currently in production. One of my tasks is to find publishers for these volumes, which are largely based on papers presented at conferences I help to organize at my university in conjunction with the Irma Rangel Public Policy Institute. At the beginning of my edited volume odyssey, I walked around the bookrooms at the annual APSA and Midwest Political Science Association conferences, buttonholing press editors with such unwelcome lines as "I'd like to discuss a volume I'm editing." I have seen editors physically recoil at this statement. I might as well have offered a rabid squirrel. Yet publish volumes they do. Some press editors are even in denial, claiming they do not really consider them, although the books in the booth belie the claim.

Are they even books, or some form of lesser publication? The language and categories we use are equivocal. Sometimes they are called edited volumes and other times edited books. Some scholars include them in the "Book" section of their CVs, while others list them separately as "Edited Volumes." Are the former trying to bulk up their book count, or do they believe that volumes make contributions worthy of the book designation?

David L. Leal is associate professor of government and director of the Irma Rangel Public Policy Institute at the University of Texas at Austin. He is the co-editor of seven volumes, including the recent Immigration and Public Opinion in Liberal Democracies (Routledge 2012). He can be reached atdleal@austin.utexas.edu.
For a product with so little respect, so apparently inconsequential to academic careers, and so little encouraged by publishers, the edited volume is hardly rare. Volumes and chapters can be found on most faculty CVs, at conference bookrooms, on syllabi, and on your own bookshelves. Why do so many people edit volumes and write chapters for so little apparent reward?

The conventional wisdom includes the following claims: chapters are written by the editors' "friends and neighbors" who may or may not be the most appropriate contributors; volumes are often thematically incoherent; and chapters in volumes vary considerably in quality. However, we should consider the possibility that smart, busy people sometimes edit volumes and write chapters for good, scholarly reasons. Based on my experience with both, as well as conversations with many faculty and publishers, I suggest the following reasons why these publication formats deserve to be taken more seriously.

\section{CONTRIBUTIONS}

First, edited volumes can bring together a greater variety of skills and knowledge than a traditional book. The result may contain more perspectives, analyze more data, incorporate research from more disciplines, and use a wider variety of methodologies. When the contributors bring different expertise to bear, the division of labor can lead to better and more timely treatments.

Writing a chapter simultaneously provides an opportunity to take part in a group project. If a volume is preceded by a conference, the participants not only write a chapter but can help shape the other chapters. In a recent New York Times Sunday Review piece (on the benefits of introversion, no less), Susan Cain (2012) noted that "recent studies suggest that influential academic work is increasingly conducted by teams rather than by individuals. (Although teams whose members collaborate remotely, from separate universities, appear to be the most influential of all.)" To the degree that volumes promote such teamwork, they are an important research format.

Volumes are also ideal opportunities to create an interdisciplinary product. A typical volume may have a dozen chapters, so it is 
easy to find room for scholars from other disciplines. Such volumes will be of interest to a wider than usual audience, so your work may be read outside of your discipline. Similarly, a volume may address an emerging topic in a developing field that has relatively few authored books. Therefore, a timely volume not only contributes to knowledge but may also encourage subsequent work.

For individual scholars, a book chapter can provide a rare opportunity to say what they think. Journal articles and books are expected to follow certain conventions, but a book chapter is evaluated more flexibly. This frees the contributor to be bold, to experiment, to draw conclusions relevant to nonacademic readers, to contribute a piece to a larger puzzle, and to generally say what needs to be said. Contributors can write with unusual freedom yet be structured by baseline academic expectations. This format may well create a wider quality distribution, but the positive end of the tail will contain important and creative work.

A chapter may also enhance the likelihood of your work being read by students, especially if published in a well-organized volume designed for classroom adoption. It is increasingly difficult to assign traditional monographs to undergraduate classesmany are expensive and typically useful for just one or two weeks of a term. Volumes, by contrast, cover more ground and are there- theme issues of journals. These issues are often useful, and their number is rising, especially as journals move to five or six issues per year. What is the difference between a set of papers published in book format versus journal format?

One difference is peer review. Each journal article is individually and anonymously reviewed by at least two or three experts in related fields. For volumes (setting aside the debate about singleblind manuscript reviews), the reviewers comment on all chapters. The chapters can be varied, which is a potential strength of volumes, but a reviewer may not be able to discuss all chapters with equal authority.

However, chapters are not blog posts or tweets-they are evaluated by professionals at multiple levels.

- From the start, the volume editors are motivated to include chapters that make scholarly contributions. Their name is on the volume, so their own interests dictate attention to the quality of the contents.

- Volumes are typically peer reviewed and must be approved by some sort of board (a faculty board for university presses, and a group of publishing professionals for commercialacademic presses).

\section{Because they can be more creative and diverse in their ideas, approaches, and coverage, edited volumes are sometimes more appealing readings. Edited volumes are also useful in classes when faculty want to assign readings beyond standard textbooks but feel that monographs and journal articles can be too specialized; used in this way, edited volumes can function as a class reader.}

fore relevant to more class weeks. Because they can be more creative and diverse in their ideas, approaches, and coverage, edited volumes are sometimes more appealing readings. Edited volumes are also useful in classes when faculty want to assign readings beyond standard textbooks but feel that monographs and journal articles can be too specialized; used in this way, edited volumes can function as a class reader.

In addition, a chapter may provide an opportunity to become better integrated into a scholarly community. Especially for graduate students and junior faculty, writing a chapter can help to claim intellectual turf and establish one's place in a field. It can simultaneously allow emerging scholars to demonstrate their research skills to a wider audience. A chapter can include a slice of a dissertation, discuss insights from field research, or develop an empirical finding in a way that does not preclude publication of the larger project. Such work can resemble the "research notes" found in some journals.

Publishing a chapter may also make career sense for scholars in liberal arts and other colleges where teaching a large number of classes is the norm. These faculty may not have the time or support to regularly publish articles or monographs, but their teaching, reading, and research generates insights that the discipline needs to hear. A book chapter is an opportunity to make such a contribution.

\section{QUALITY}

Even if the chapters in a volume are less unified than they should be-a frequent criticism-we might see a parallel in the special
- Volumes, like books, are sometimes part of a series, and the series editor may evaluate the project.

- Chapters may receive comments from other participants in the project, especially if the project began as a small conference.

- Because press editors often see volumes as money pits, they subject volume proposals to an additional degree of scrutiny. Although these editors do not necessarily have an academic background in the relevant social science discipline, they develop a good ear for field developments and attractive ideas.

- While the rigorous, double-blind, and exacting journal peerreview process has many pluses, it sometimes weeds out papers with new ideas, useful innovations, and valuable "big picture" discussion. Edited volumes provide a rare home for such writing.

Taken together, the preceding factors provide a reasonable standard of review that separates volumes from less-scholarly forms of writing. While some volumes are of higher quality than others, this variation is true of every type of publication. The issue is not the format but the care taken by the contributors and editors.

\section{RECOMMENDATIONS}

To improve the status of volumes and chapters in the social sciences, I have several suggestions. First, their content needs to be more easily grasped. For instance, almost all journal articles are accompanied by abstracts, but this is not the general practice for 
chapters. Why not? For the future, every publisher and editor should insist that each chapter begin with an abstract (and make these abstracts available on the volume's website). Be aware that some publishers will resist changing long-established formatting practices.

As with journal articles, book chapters need to be searchable. When electronically searching the holdings and online resources of a university library, readers should ideally receive a list of both articles and chapters. Chapters also need to be immediately accessible. The traditional method of scholarly book publishing is to print paper copies, which are then placed on bookshelves. Locked in this format, a creative chapter may have difficulty finding an audience. Although technology is slowly making books and chapters electronically available (for example, through Project Muse), a chapter should appear as a clickable, downloadable option in online library searches, just like a journal article. (In the interests of full disclosure, I edit a book series for a publisher that promotes this concept by electronically treating book chapters as journal articles and edited volumes as journal issues.) Without this access, how many potential readers will walk to the library to photocopy a chapter?

The scholarly impact of volumes should be quantitatively assessed. For this, volumes and chapters need to be separately included in citation counts. To my knowledge, no system will "count" a volume if a chapter from that volume is cited. The Social Science Citation Index/Web of Science lists the citations of the journal articles in its database, including volumes (if the volume itself is cited) and chapters, and Google Scholar includes the citations of many types of papers and publications. Therefore, we can count chapter citations, but it is more difficult to assess the overall contribution of volumes. The alternative is a time-consuming assessment of the impact of volumes in specific fields. For example, Freeman (2011) discussed all the comparative immigration edited volumes he could find that were published from 1981 to 2004. We might start by assessing the impact of our own publications. You might find, as did I, that some of your chapters are better cited than some of your articles.

\section{FUTURE}

In the future, the edited volume format will likely persist-not only because technology is shrinking the accessibility gap between articles and chapters, but also because volumes serve a valuable and unique role. In Small World, the funniest campus novel ever written, author and professor David Lodge (1984) begins with a quote from Nathaniel Hawthorne:

When a writer calls his work a Romance, it need hardly be observed that he wishes to claim a certain latitude, both as to its fashion and material, which he would not have felt himself entitled to assume had he professed to be writing a Novel.

This example may provide another window on the persistence of the volume and the chapter. We have more scholarly latitude with a Volume than with a Book, and we are freed to write a Chapter instead of an Article. We can contribute to a larger project, say something on our minds, pursue new ideas, work in groups, write for new and interdisciplinary audiences, and publish work readable to students and practitioners. We should appreciate this chance to be creative rather than dismiss a long-standing format that seems well suited to our more collaborative scholarly future.

\section{ACKNOWLEDGMENTS}

Thanks to Gary Freeman, Kurt Weyland, and an anonymous reviewer for helpful comments and suggestions.

\section{REFERENCES}

Cain, Susan. 2012. "The Rise of the New Groupthink." New York Times Sunday Review, January 15. http://www.nytimes.com/2012/o1/15/opinion/sunday/therise-of-the-new-groupthink.html?pagewanted=all\&_r=o

Freeman, Gary P. 2011. "Immigration, Incorporation, and Diversity in Western Europe and the United States: Comparative Perspectives." American Behavioral Scientist 55 (12): 1535-40.

Lodge, David. 1984. Small World. New York: Penguin. 